\title{
SEEING THE LIGHT
}

\section{Dear Reader,}

It is quite amazing how many vehicles with faulty or incorrect lights could be seen on the roads in recent months. Cars, buses and trucks alike, and all parts of the vehicle's exterior lighting, from headlights and brake lights to number plate lamps, were affected. It is amazing because, during October, all drivers were able to have their car's lights checked free of charge as part of the German annual campaign run by the automotive associations ZDK and DVW.

The title of the press release published by the two institutions almost sounds like resignation: "No improvement in sight". There was even a slight rise in the percentage of defective vehicles among drivers who are dutiful and took the trouble to have their cars checked. Overall, $35.2 \%$ of the cars tested at approximately 38,000 inspection stations had faulty lighting (previous year: $34.3 \%$ ). People seem to find it difficult to keep their lights in working order.

"See and be seen" is the most important principle in road traffic. But not many seem to bother, even though this carelessness can also be a danger to others. When will they finally see the light? In the meantime, drivers are paying a penalty for this cavalier attitude towards lighting and safety when take their car for its regular TÜV roadworthiness test. Even a broken lamp is now classified as a safety-relevant fault, which means that the vehicle will fail the test and have to be re-checked - for an additional fee, of course. In the past, it would have been classed as a minor fault and a test certificate would have been issued nevertheless.

According to the 2014 annual report by the TÜV vehicle inspection body, defective lighting already tops the list of vehicle faults at the first inspection after three years, with a failure rate of $7 \%$ - far ahead of oil leaks (1.1\%) and the braking system (1.0\%). For older vehicles, the trend is even worse. Among the five-year-old vehicles tested, $11.5 \%$ had a fault in the lighting system. For sevenyear-olds, the figure was $15.8 \%$, and for nine-year-old cars, it rose to $21.6 \%$ and after eleven years, even one in four vehicles $(24.9 \%)$ was defective.

But there is also a positive trend, resulting from more modern halogen lamps, xenon headlights and soon also LEDs, which are less affected by voltage fluctuations and last longer. The TÜV inspectors also point out that the wider use of on-board diagnosis means that faults are noticed sooner. So why not make it mandatory to have a light warning symbol in the cockpit? The state of the catalytic converter and the tyre pressure have already made it into the instrument cluster.

In this month's Cover Story, we are presenting new LED lighting systems from Audi and Hella. I look forward to seeing how these innovations will have influenced the lighting test of vehicles in eleven years' time.

Best regards,

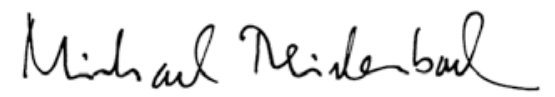

DIPL.-ING. MICHAEL REICHENBACH, Vice-Editor in Chief

Wiesbaden, 28 January 2014

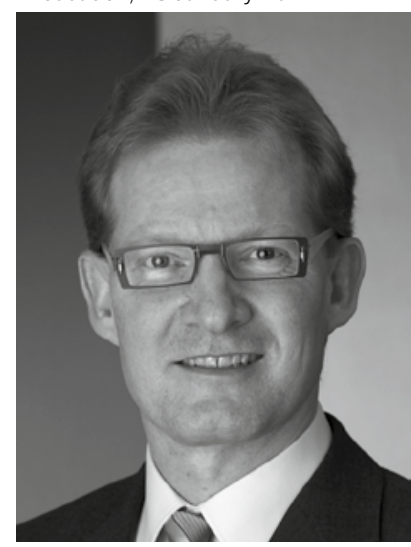

